\title{
MORTALITY ANALYSIS OF BURNS IN A DEVELOPING COUNTRY: THE CAMEROONIAN EXPERIENCE
}

Ndung Ako Forbinake ${ }^{1 *}$, Dongmo Gael2 ${ }^{2}$ Ohandza Claude ${ }^{3}$, Chichom-Mefire Alain ${ }^{4,5}$, Fokam Pius ${ }^{5,6}$, Beyiha Gerard ${ }^{6,7}$, Ngowe Ngowe Marcelin 5 .

1 Meri District Hospital, Meri, Far-North, Cameroon.

2 Faculty of Medicine and Biomedical Sciences, University of Yaounde 1, Yaounde, Cameroon.

3 Dzeng Medicalised Health Centre, Dzeng, Cameroon.

4 Douala Gynaeco-Obstetric and Paediatric Hospital, Douala, Cameroon.

$5 \quad$ Faculty of Health Sciences, University of Buea, Buea, Cameroon.

6 Douala General Hospital, Douala, Cameroon.

$7 \quad$ Faculty of Medicine and pharmaceutical sciences, University of Douala, Cameroon.

*Corresponding Author: Ndung Ako Forbinake, MD. Meri District Hospital, Far-North, Cameroon.

MORTALITY ANALYSIS OF BURNS IN A DEVELOPING COUNTRY: THE CAMEROONIAN EXPERIENCE

\begin{abstract}
Background: Burns are the leading causes of disability-adjusted life-years (DALYs) lost in low- and middleincome countries. The survival outcome in the Douala General Hospital was lower than the survival outcome predictions in high income countries.
\end{abstract}


Methods: It was a retrospective observational study carried out from the $1^{\text {st }}$ of January 2008 to the $31^{\text {st }}$ of December 2015 in the Burn Unit of the Douala General Hospital. An adapted questionnaire was used to collect demographic data, burn agents, burn depth; diagnostic delay, burn surface area, mortality and its causes. Data was transferred to Microsoft Excel 2015 and Statistical Package for Social Sciences (SPSS) version 20.0 for data analysis.

Results: During this 8 year period, 453 patients were studied and most ( $n=339,74.8 \%)$ patients were admitted. Mortality was high ( $n=104,23.0 \%)$. Amongst those who died, the burn agents responsible were, flames ( $n=69,66.3 \%)$, electricity $(n=15,14.4 \%)$, water $(n=12,11.5 \%)$, contact $(n=5,4.8 \%)$, Oil $(n=2,1.9 \%)$ and chemicals $(n=1,1.1 \%)$. The causes of death were shock $(n=36,34.0 \%)$, sepsis $(n=25,24.0 \%)$, acute respiratory distress $(n=25,24.0 \%)$, acute renal failure $(n=6,6 \%)$, severe anaemia $(n=4,4.0 \%)$ and unrecorded causes $(n=8,8 \%)$.

Conclusion: A quarter of all patients died mostly from flame, electricity and water burns. Increase in burn depth and burn surface area worsened the prognosis. Shock (the commonest cause of death), sepsis, acute respiratory distress, acute renal failure and wound infection were significantly associated to mortality.

Keywords: Burns, Causes, Agents, Mortality.

\section{Background}

Burns are a serious public health problem accounting for 265000 annual death from fires alone worldwide [1]. Burns are among the leading causes of disability-adjusted life-years (DALYs) lost in low- and middle-income countries. In 2004, about 11 million people worldwide suffered from burns, severe enough to require medical attention [2]. Burn injuries are a major cause of prolonged hospital stays, disfigurement, disability, and death in Africa [3] The survival outcome in our setting (Douala General Hospital) was lower than the survival outcome predictions in high income or developed countries [4]. 


\section{Methods}

\section{Study design and setting}

This study was a retrospective observational study with review of medical records over a period of 8 years, from January $1^{\text {st }} 2008$ to December $31^{\text {st }} 2015$. The Douala General Hospital is a tertiary hospital in the Cameroon health system and has the only burn unit in the public sector.

\section{Data collection \& statistical analysis}

The variables of each patient were extracted from the hospitalisation files and filled in the questionnaire.

The variables of each patient were extracted and filled in the questionnaire. This information was transferred from the data collection sheet into Microsoft Office Excel Worksheet 2015 and then coded into the Statistical Package for the Social Sciences (SPSS) version 20.0. The Pearson Chi-square was used to determine associations between categorical variables and mortality with the level of significance set at 0.05 ( $p$-value). Mortality rate was calculated thus,

$$
\text { Mortality rate }=\frac{\text { Number of patients who died }}{\text { Total number of patients }} \times 100
$$




\section{Results}

During this 8 year period, 453 patients were studied and the mean age was $25.2 \pm 17.77$ years with a male predominance ( $n=288,63.6 \%$ ). The mortality rate was $23.0 \%$ (104 patients) from different aetiologies. In this study, sex and age didn't seem to influence mortality. (See Table 1 and 2)

Table 1: Sex distribution of patients who died.

Table 2: Age distribution of patients who died.

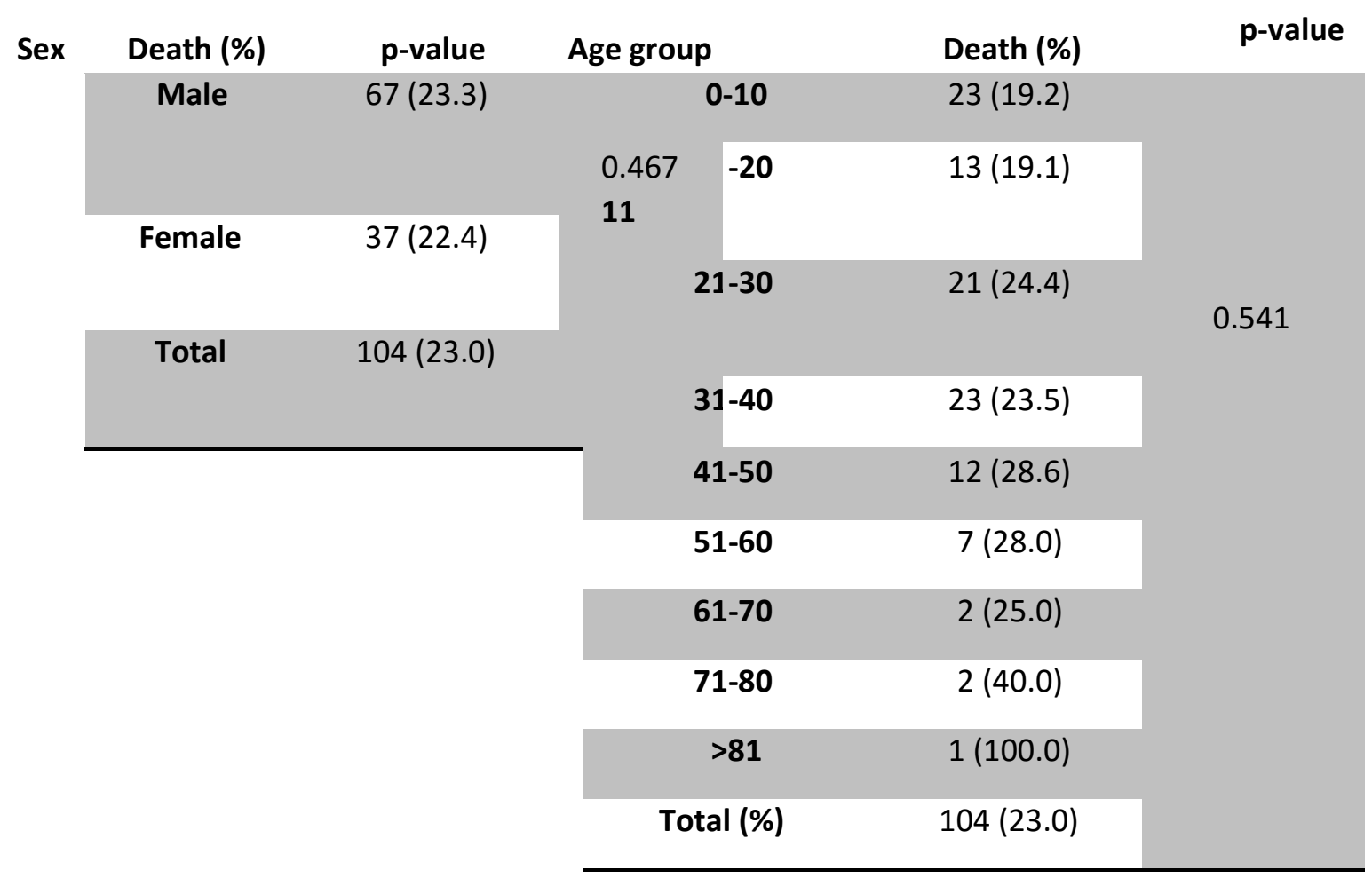

Amongst those who died, the burns were caused by different agents mostly from flames ( $n=69,66.3 \%)$ and others illustrated below: 
Figure 1: Distribution of patients who died according to burn agent.

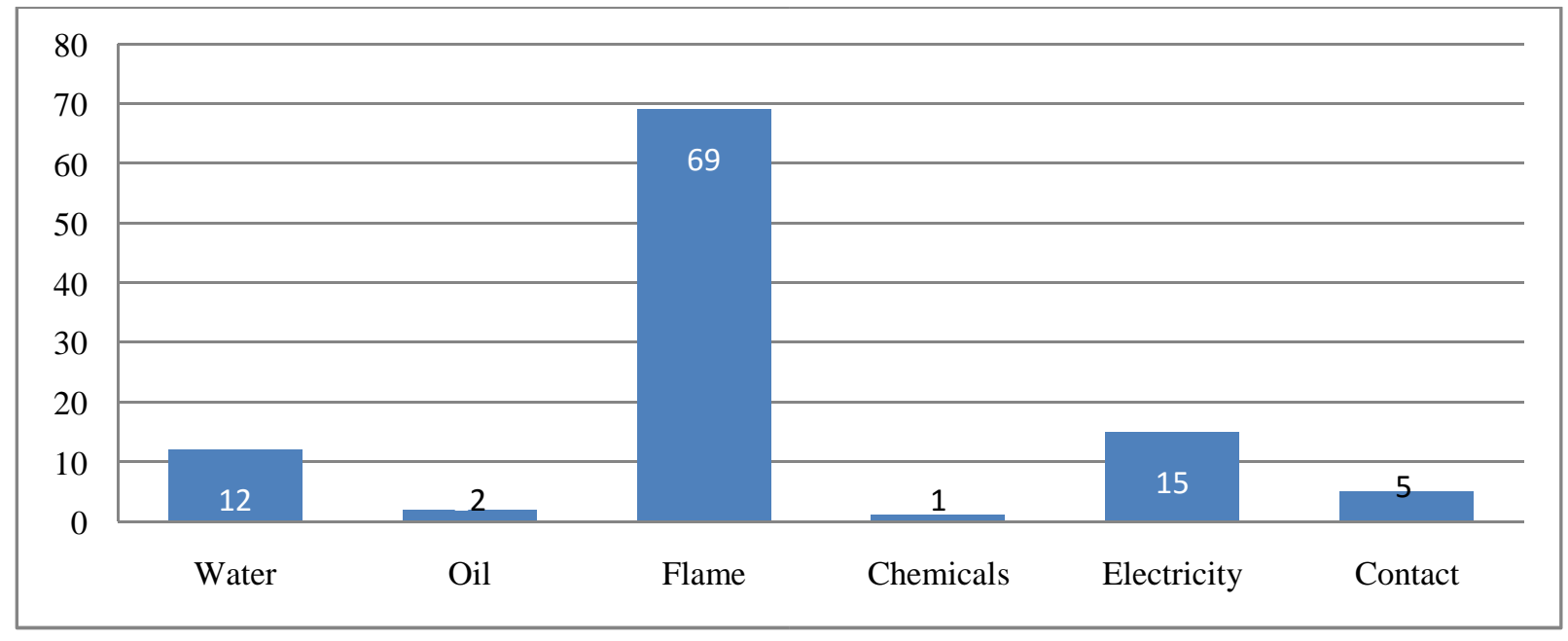

Some of these burn agents were significantly associated with mortality as shown below:

Table 3: Burn agents and mortality.

\begin{tabular}{ccccc}
\hline Burn Agent & Survival (\%) & Death (\%) & Total (\%) & p-value \\
\hline Water & $99(89.2)$ & $12(10.8)$ & $111(24.5)$ & 0.001 \\
\hline Oil & $25(92.6)$ & $2(7.4)$ & $27(6.0)$ & 0.031 \\
Flame & $100(59.2)$ & $69(40.8)$ & $169(37.3)$ & 0.001 \\
\hline Chemical & $6(85.7)$ & $1(14.3)$ & $7(1.5)$ & 0.496 \\
\hline Electrical & $104(87.4)$ & $15(12.6)$ & $119(26.3)$ & 0.001 \\
\hline Contact & $15(75.0)$ & $5(25.0)$ & $20(4.4)$ & 0.033 \\
\hline Total & $349(77.0)$ & $104(23.0)$ & $453(100.0)$ & - \\
\hline
\end{tabular}

In our study, vis-à-vis the clinical presentation, burn depth influenced mortality as all the forms were statistically associated to mortality $(p=0.001)$. Nonetheless, it was demonstrated that those with first degree $(R=-0.310)$ had less propensity to die than patients with second $(R=+0.268)$ and third degree burns $(R=+0.364)$. 
(See Table 4)

The total body surface area burnt was also statistically associated to mortality. (See Table 5)

Table 4: Distribution of patients who died according to Table 5: Mortality according to burn surface area. burn depth.

\begin{tabular}{cccc}
\hline $\begin{array}{c}\text { Burn } \\
\text { depth }\end{array}$ & Death (\%) & p-value & $\mathbf{R}$ \\
$\begin{array}{c}\text { First } \\
\text { degree }\end{array}$ & $8(6.7)$ & 0.001 & -0.310 \\
\hline $\begin{array}{c}\text { Second } \\
\text { degree }\end{array}$ & $69(31.0)$ & 0.001 & $+\mathbf{0 . 2 6 8}$ \\
$\begin{array}{c}\text { Third } \\
\text { degree }\end{array}$ & $27(47.6)$ & 0.001 & +0.364 \\
\hline Total & $104(23.0)$ & - & - \\
\hline
\end{tabular}

\begin{tabular}{ccc}
\hline $\begin{array}{c}\text { \% Burns } \\
\text { surface area }\end{array}$ & Death (\%) & p-value \\
\hline $\mathbf{0 - 9}$ & $2(1.0)$ & \\
$\mathbf{1 0 - 1 9}$ & $4(5.5)$ & \\
$\mathbf{2 0 - 3 9}$ & $24(29.6)$ & $<\mathbf{0 . 0 0 1}$ \\
$\mathbf{4 0 - 5 9}$ & $25(56.8)$ & \\
$\geq \mathbf{6 0}$ & $49(94.2)$ & \\
Total & $104(23.0)$ & \\
\hline
\end{tabular}

Table 6: Mortality according to time of arrival after injury.

\begin{tabular}{ccccc}
\hline Time & Survival (\%) & Death (\%) & Total (\%) & p-value \\
\hline $\mathbf{0 - 1 h r}$ & $150(82.0)$ & $33(18.0)$ & $183(40.4)$ & 0.005 \\
\hline $\mathbf{2 - 8 h r s}$ & $92(76.0)$ & $29(24.0)$ & $121(26.7)$ & 0.040 \\
\hline 9-24hrs & $31(57.4)$ & $23(42.6)$ & $54(11.9)$ & 0.758 \\
\hline 25-48hrs & $27(79.4)$ & $7(20.6)$ & $34(7.5)$ & $\mathbf{0 . 0 0 1}$ \\
\hline 488hrs & $49(80.3)$ & $12(19.7)$ & $61(13.5)$ & 0.733 \\
\hline Total & $349(77.0)$ & $104(23.0)$ & $453(100.0)$ & 0.005 \\
\hline
\end{tabular}


The time of arrival after injury was statistically significant with respect to mortality for those who came to the burn unit between 25 to 48 hours after injury.

Many patients ( $n=384,84.8 \%$ ) experienced complications during this 8 year time frame. The table below shows which of the complications were statistically significant with mortality.

Table 7: Mortality with respect to complications faced.

\begin{tabular}{ccccc}
\hline Complications & Survival (\%) & Death (\%) & Total (\%) & p-value \\
Shock & $12(12.4 \%)$ & $85(87.6)$ & $97(21.4)$ & $\mathbf{0 . 0 0 1}$ \\
Sepsis & $34(54.8)$ & $28(45.2)$ & $62(13.7)$ & $\mathbf{0 . 0 0 1}$ \\
Acute respiratory distress & $6(10.5)$ & $51(89.5)$ & $57(12.6)$ & $\mathbf{0 . 0 0 1}$ \\
Anaemia & $34(64.2)$ & $19(35.8)$ & $53(11.7)$ & 0.017 \\
Acute renal failure & $1(6.7)$ & $14(93.3)$ & $15(3.3)$ & $\mathbf{0 . 0 0 1}$ \\
Wound infection & $12(12.4)$ & $85(87.6)$ & $97(21.4)$ & $\mathbf{0 . 0 0 1}$ \\
\hline Gangrene & $46(85.2)$ & $8(14.8)$ & $54(11.9)$ & 0.086 \\
\hline
\end{tabular}

The causes of death were shock $(n=36,34.0 \%)$ followed by sepsis $(n=25,24.0 \%)$, acute respiratory distress $(n=25,24.0 \%)$ and others

Figure 2: Distribution of burn mortality causes. 


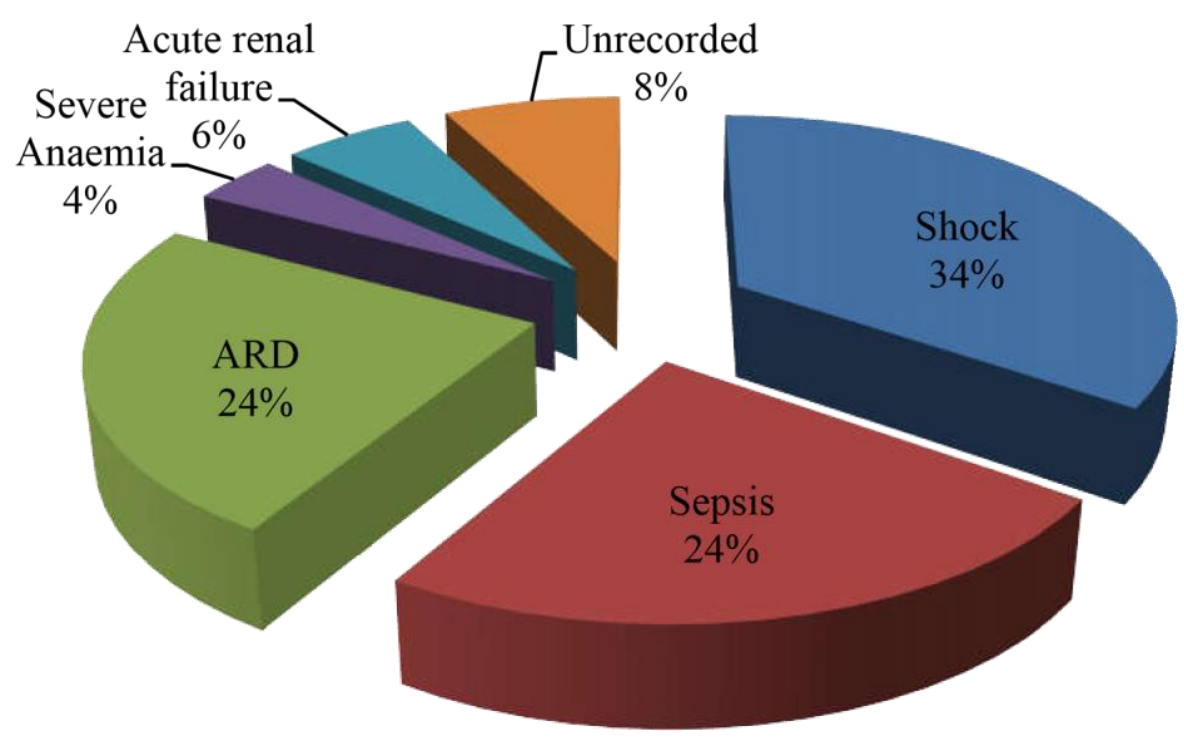

\section{Discussion}

The mortality rate of this study was $23.0 \%$. This was similar to other studies in Cameroon, Nigeria and Morocco [5-9]. This mortality rate was lower than other studies in Cameroon, Nigeria, Ghana and Iran [10-13]. On the other hand, mortality rate of this study was higher than that of other studies in Nigeria, Singapore and China [14-16].

For studies which had a higher mortality rate than that of this study; according to Amengle et. al, the mortality was $41.2 \%$ this was because, these was it was due to the high incidence of severe burns in these children [10]. Kalayi in Zaria, Nigeria had a mortality rate of $35 \%$ was because $52 \%$ of admissions were children below the age of five years with severe burns [11]. Nguema et.al, in Gabon had a death rate of $54.8 \%$. This was because this study was conducted in an intensive care unit [12]. Soltani et.al, in Tehran, Iran had a mortality rate of $59.48 \%$. This was because patients with below $40 \%$ of burned surface constituted $52.5 \%$ of injuries so more cases of severe burns [13].

For studies which had a lower mortality rate than that of this study; Dongo et.al, conducted a study in Irrua, Nigeria in 2007 revealing a $9.72 \%$ mortality [14]. Song \& Chua in Singapore had a mortality rate of $4.61 \%$. This was because patients with burn size of $10 \%$ TBSA and less made up the majority of admissions at $70.7 \%$ while patients with burn size $30 \%$ TBSA and more made up $8.2 \%$ [15]. Jie \& Baoren in China had an overall mortality rate of $0.86 \%$. The high survival rate, may relate primarily to the low percentages of older patients and of patients with severe burns [16]. 
Mortality in males $64.4 \%$ was higher than that in females $35.6 \%$. This is similar to a study conducted by Olaitan \& Jiburum in Nigeria [6]. In our study, it was found that sex and mortality were not statistically significant $(p=0.467)$. The highest mortality rate was the 0 - 10 and the $31-40$ years age group (22.1\%) followed by the $21-30$ years age group (20.1\%) and

the lowest being those aged above 80 years; this is similar to results obtained Olaitan and Jiburum, where age and mortality were not statistically significant with $p=0.541$.

From this study, the percentage survival drops as the burn surface area increases. This is because the more the surface area burned, the more fluids lost, more liability to infection and multiple organ shut down. This was statistically significant in this study with $p<0.001$.

In this study, shock (34\%) was the most common cause of death, sepsis (24\%), acute respiratory distress (24\%), severe anaemia (4\%), acute renal failure (6\%) and in $8 \%$ no specific cause of death was indicated. This is unlike the study conducted by Olaitan \& Jiburum in Nigeria where acute renal failure (24 cases, $42.1 \%$ ) was the commonest cause of death, septicaemia (18 cases, 31.6\%), acute respiratory syndrome (5 cases, 8.7\%), shock (4 cases, 7.0\%), and upper gastrointestinal bleeding due to peptic ulcer and severe anaemia (1 case each, $1.8 \%$ ) and in four cases (7.0\%) no specific cause of death was indicated [6]. Martina \& Wardhana in Indonesia, found out that death was caused by septicaemia (42.1\%), multiple organ failure (31.6\%), systemic inflammatory response syndrome $(17,6 \%)$, and acute respiratory distress syndrome (8.7\%) [17].

In this study mortality with respect to complications was statistically significant with shock, sepsis, acute respiratory distress, acute renal failure and wound infection all with $p<0.001$.

Most patients $(31.7 \%)$ who died came in within 0 to 1 hour. This is because severe burns are generally rapidly rushed to the hospital, in this case, the Douala Burn Centre. This is could be due to delayed referral from primary hospital care, 
ignorance and poverty. In this study, mortality was statistically significant with those who came 25-48 hours after burn $(p<0.001)$ this is probably because many patients were referred still unstable.

\section{Conclusion}

A quarter of all patients died mostly from flame, electricity and water burns. Increase in burn depth and burnt surface area worsened the prognosis. Shock (the commonest cause of death), sepsis, acute respiratory distress, acute renal failure and wound infection were significantly associated to mortality.

\section{Abbreviation}

ARD: Acute Respiratory Distress

\section{Competing interest}

The authors declare that they have no competing interests in this section.

\section{Funding}

None

\section{Authors' contribution}

NAF collected data from files of patients. NAF wrote the manuscript. CMA, FP and NNM supervised this work. First corrections were done by CMA. All authors approved final manuscript and are responsible for it.

\section{Acknowledgement}


I extend my sincere gratitude to the staff of the burn unit.

\section{Author details}

Ndung Ako Forbinake, MD. Meri District Hospital, Far-North, Cameroon.

\section{References}

1. World Health Organization. Burns. Available from:

http://www.who.int/violence_injury_prevention/other_injury/burns/en/2. World Health Organization. World health statistics, Geneva: World Health Organization, 2010. Available from:

\section{http://site.ebrary.com/id/10393307}

3. Outwater AH, Ismail H, Mgalilwa L, Justin Temu M, Mbembati NA. Burns in Tanzania: morbidity and mortality, causes and risk factors: a review. Int J Burns Trauma. 2013; 3(1):18-29. 4. Verla VS, Beyiha G, Ebesoh DN. An Assessment of Abbreviated Burn Severity Index (ABSI) in Douala, Cameroon. Available from: http://www.ajih.net/public/art25.php

5. Beyiha G, Binam F, Batamack JF, Sosso M.A. Traitement et Pronostic de la brulure grave au centre des grands brules de Douala, Cameroun. Available from: http://www.medbc.com/annals/review/vol_13/num_3/text/vol13n3p131.htm 6. Olaitan PB, Jiburum BC. Analysis of burn mortality in a burns centre. Annals of burns and fire disasters. 2006; $19(2): 59$.

7. Olaitan PB, Fadiora SO, Agodirin OS. Burn injuries in a young Nigerian teaching hospital. Ann Burns Fire Disasters. 2007. 
8. Olaitan PB, Iyidobi EC, Olaitan JO, Ogbonnaya IS. Burns and scalds: First-aid home treatment and implications at Enugu, Nigeria. Annals of burns and fire disasters. 2004; 17(2):61-3.

9. Boukind EA, Chafiki N, Bahecar N., Alibou F, Terrab S, Boumzebra Cl., Zerouali OX. Les Brules: Profil Epidemologique et Elements De Prevention A Propos De 1499 Patients Hospitalises A L'unite Des Brules De Casablanca, Maroc. Available from: http://www.medbc.com/annals/review/vol_7/num_2/text/vol7n2p57.htm

10. Amengle LA, Bengono RB, Mbengono JM, Beyiha G, Minkande JZ, Abena MO. Aspects épidémiologiques et pronostiques des brulures graves chez l'enfant. Available from: http://www.hsdfmsb.org/index.php/hsd/article/view/474

11. Kalayi GD. Mortality from burns in Zaria: an experience in a developing economy. East Afr Med J. 2006.

12. Mock CN, Adzotor E, Denno D, Conklin E, Rivara F. Admissions for injury at a rural hospital in Ghana: implications for prevention in the developing world. Am J Public Health. 1995.

13. Soltani K, Zand R, Mirghasemi A. Epidemiology and mortality of burns in Tehran, Iran. Burns. 1998; 24(4):325-8.

14. Dongo AE, Irekpita EE, Oseghale LO, Ogbebor CE, Iyamu CE, Onuminya JE. A five-year review of burn injuries in Irrua. BMC Health Serv Res.

15. Song C, Chua A. Epidemiology of burn injuries in Singapore from 1997 to 2003. Burns. 2005; 31 Suppl 1:S18-26.

16. Jie X, Baoren C. Mortality rates among 5321 patients with burns admitted to a burn unit in China: 19801998. Burns. 2003; 29(3):239-45. 17. Martina NR, Wardhana A. Mortality analysis of adult burn patients. Jurnal Plastik Rekonstruks. Available from:

http://www.jprjournal.com/index.php/jpr/article/view/155. 